\title{
Distribution and metabolism in healthy volunteers of disodium azodisalicylate, a potential therapeutic agent for ulcerative colitis
}

\author{
C P WILlOUGHBY, J K ARONSON, H AGBACK, \\ N O BODIN, and S C TRUELOVE*
}

From the Gastroenterology Unit and MRC Unit of Clinical Pharmacology, Radcliffe Infirmary, Oxford, and the Departments of Chemical Research and Biological Analysis, Pharmacia AB, Uppsala, Sweden

SUMMARY A series of experiments has been performed in healthy male volunteers to investigate the disposition of orally administered disodium azodisalicylate, a potentially useful drug for the treatment of ulcerative colitis. The drug was given by mouth in doses of up to $2 \mathrm{~g}$ a day for six weeks and there were no adverse effects. Serum concentrations of the intact compound were low and the serum half-time was 4-12.8 days, probably because of a combination of a low clearance rate and a high apparent volume of distribution. Less than 5\% of the ingested dose was excreted unchanged in the urine. Circulating concentrations of 5-ASA and N-acetyl-5-ASA were low and $30 \%$ of the equivalent daily dose was excreted in the urine, predominantly as N-acetyl-5-ASA. In most subjects more than $30 \%$ of the equivalent daily dose of 5-ASA was recovered from the faeces, either as 5-ASA itself or as the acetylated derivative. As 5-ASA has been shown to be the active therapeutic moiety of sulphasalazine, disodium azodisalicylate appears to be suitable for therapeutic trial in ulcerative colitis.

Sulphasalazine (salicylazosulphapyridine) is well established as a valuable form of treatment for ulcerative colitis. It is of value in treating an acute attack of the disease ${ }^{12}$ and is especially useful as maintenance therapy for reducing the recurrence rate, which is lowered to about one quarter of that in untreated subjects. ${ }^{34}$

The mode of action of sulphasalazine is unknown but certain important aspects of its metabolism have been established. When taken by mouth (the usual form of administration) most of the drug reaches the colon intact and is there split by the colonic bacteria into sulphapyridine and 5-aminosalicylic acid (5ASA). Virtually all the sulphapyridine is absorbed and is then excreted in the urine in conjugated form. Some of the 5-ASA is absorbed and is excreted in the urine as $\mathrm{N}$-acetyl-5-ASA. A large proportion of the 5-ASA is excreted in the faeces. 5

A previous experiment in patients with ulcerative

* Address for reprints: Dr S C Truelove, Radcliffe Infirmary, Oxford OX2 $6 \mathrm{HE}$.

Received for publication 26 March 1982 colitis provided strong evidence that the 5-ASA is the active therapeutic moiety of sulphasalazine, ${ }^{7}$ and this finding has received independent confirmation. ${ }^{8}$

As the sulphapyridine functions simply as a carrier to transport the 5-ASA to the inflamed colon, and as it is responsible for virtually all the adverse effects of sulphasalazine, ${ }^{9}$ it is desirable to search for a compound which, when taken by mouth, will liberate 5-ASA in the colon, without releasing sulphapyridine or any other agent likely to cause adverse affects. When sulphasalazine is used as maintenance therapy for ulcerative colitis, the bigger the dose, the lower is the relapse rate but at the price of increased adverse effects. ${ }^{10} \mathrm{~A}$ compound not containing sulphapyridine might therefore permit higher concentrations of 5-ASA to be achieved in the colonic lumen without sideeffects.

A promising candidate is azodisalicylic acid, which consists of two salicylate radicals linked by an azo bond. Unpublished studies in Oxford using thin-layer chromatography have shown that human 
colonic bacteria, both aerobic and anaerobic, are capable of splitting this molecule with the release of two molecules of free 5-ASA (Fig. 1). Azodisalicylic acid is a very fine yellow powder which is difficult to handle physically because its particles adhere to each other and to various surfaces. For pharmaceutical reasons, the disodium salt has therefore been used.

As a preliminary to clinical studies of the efficacy of disodium azodisalicylate in patients with ulcerative colitis, we have studied the disposition of this compound in healthy volunteers.

\section{Methods}

\section{SUBJECTS}

The subjects were healthy male physicians aged between 26 and 67 years. The study was approved by the Ethics Committee of the Oxfordshire Area Health Authority.

\section{FORMULATION OF TEST SUBSTANCE}

The disodium azodisalicylate was administered in gelatin capsules, each of which contained either 125 or $250 \mathrm{mg}$ of the powdered drug with no additives.

\section{HANDLING OF SAMPLES}

\section{Blood}

Venous blood samples were withdrawn at predetermined intervals during each study. The sera were separated and stored at $-20^{\circ} \mathrm{C}$ until analysis.

\section{Urine}

The volume of each sample was measured and a $5 \mathrm{ml}$ aliquot of each was stored at $-20^{\circ} \mathrm{C}$ until analysis.

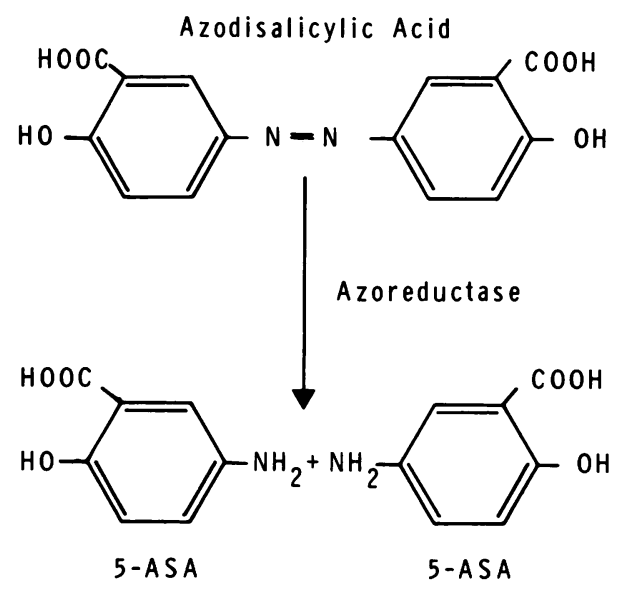

Fig. 1 Structure and cleavage of azodisalicylic acid.

\section{Faeces}

Each sample was collected in a plastic bag containing $200 \mathrm{ml} \mathbf{0 . 2 \%}$ mercuric chloride solution, which was immediately mixed thoroughly with the faeces to kill all bacteria. The contents of the bag were subsequently homogenised and the weight and volume recorded. An aliquot was extracted and treated according to the method of van Hees ${ }^{11}$ for the determination of total 5-ASA and $\mathrm{N}$-acetyl-5ASA. The final aqueous extract in phosphate buffer was stored at $-20^{\circ} \mathrm{C}$ until analysis. The same extraction procedure was carried out with faecal suspensions to which known amounts of 5-ASA had been added in order to construct standard curve.

\section{LABORATORY METHODS}

Standard haematological and biochemical measurements were performed by the routine clinical laboratories at Oxford. For the analysis of disodium azodisalicylate and its metabolites, samples of blood, urine, and faeces were obtained as detailed above and were sent to Pharmacia AB packed in dry ice in insulated containers. All samples were coded so that the chemists performing the measurements were unaware of the stage of the experiment at which any sample had been obtained. The results were subsequently collated at Oxford.

\section{ANALYTICAL METHODS}

The disodium azodisalicylate was determined in serum and urine by high performance liquid chromatography (HPLC).

After addition of the internal standard (the structural isomer disodium 3,5'-azo-bis-(6hydroxybenzoate)) the aqueous samples were acidified and the compounds extracted into ethyl acetate and then back to a neutral aqueous phase. Reversed phase chromatography of the tetrabutyl ammonium ion-pair on LiChrosorb RP 18 with methanol/water as the mobile phase was used for separation. Quantification was performed by monitoring with ultra-violet absorption at $365 \mathrm{~nm}$. The peak-height ratio was found to be a linear function of concentration; the lower limit of detection was $0.3 \mu \mathrm{mol} / \mathrm{l}(0.1 \mu \mathrm{g} / \mathrm{ml})$ for serum and $3.0 \mu \mathrm{mol} / \mathrm{l}(1.0 \mu \mathrm{g} / \mathrm{ml})$ for urine. No interference from the biological matrix or the known metabolites was observed. In order to ensure that the relative analytical error should not exceed $10 \%$, one control sample (at a randomised position unknown to the analyst) was included for every nine actual samples.

A similar HPLC method was used to determine 5-aminosalicylic acid (5-ASA, 5-amino-2hydrobenzoic acid), and its acetylated metabolite (N-acetyl-5-ASA), in serum and urine. After addition of the internal standard $(2,4$ - 
dihydroxybenzoic acid), 5-ASA was transformed into the propionyl derivative by addition of propionic anhydride. After acidification, the serum samples were extracted with diethyl ether, and the urine samples with isobutyl methyl ketone. After back-extraction to a neutral aqueous phase, the compounds were measured in a way analogous to that described for disodium azodisalicylate, except that monitoring the fluorescence emission at $435 \mathrm{~nm}$ with excitation at $312 \mathrm{~nm}$ was used for quantification. In all cases linear calibration curves were obtained. The lower limit of detection for both compounds in serum was $0.3 \mu \mathrm{mol} / \mathrm{l}(0.06 \mu \mathrm{g} / \mathrm{ml})$. In urine the corresponding values were $10 \mu \mathrm{mol} / \mathrm{l}(2 \cdot 0$ $\mu \mathrm{g} / \mathrm{ml})$ for 5-ASA and $100 \mu \mathrm{mol} / 1(20 \mu \mathrm{g} / \mathrm{ml})$ for $\mathrm{N}$-acetyl-5-ASA. No interference from the parent compound or the biological matrix was noted. The accuracy of the determinations was assessed by including control samples.

The faecal extracts were analysed by HPLC without further extraction and without the use of an internal standard. The calibration curves were linear and the lower limits of detection were similar to those for urine.

A full account of the analytical methods used will be given elsewhere (Bodin et al, to be published).

\section{PHARMACOKINETIC METHODS}

Pharmacokinetic calculations were made by the standard techniques described by Wagner. ${ }^{12}$

\section{Results}

Four separate experiments have been carried out.

\section{SINGLE DOSE EXPERIMENTS}

Eight subjects each took a single dose of $500 \mathrm{mg}$ disodium azodisalicylate after an overnight fast; no food or drink was allowed for a further two hours. Venous blood samples were collected serially over the next three days and all specimens of urine and faeces passed during the same three days were collected separately for analysis. Blood and urine samples were collected for routine investigation immediately before taking the drug and also after 72 hours.

Figure 2 shows the serum concentrations and urinary excretion rates of intact azodisalicylate in the two subjects who were at the extremes of the range of results obtained. The highest serum concentration of intact azodisalicylate observed in any subject was $19 \cdot 0 \mu \mathrm{mol} / \mathrm{l}(6 \cdot 6 \mu \mathrm{g} / \mathrm{ml})($ subject $\mathrm{K})$. In all subjects the peak serum concentration occurred at between one and two hours after ingestion but it was notable that an appreciable serum concentration was still present after 72 hours,

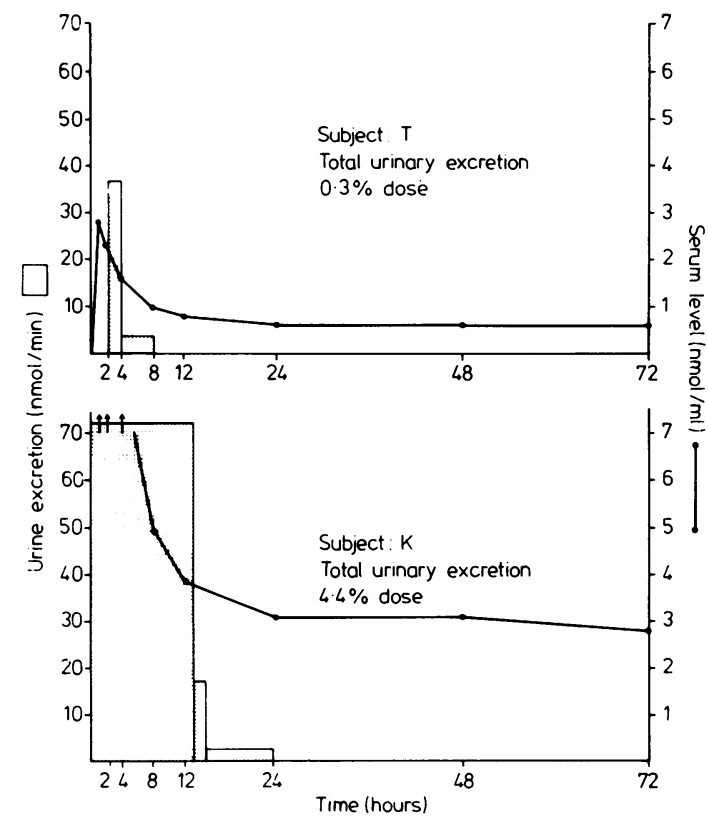

Fig. 2 Serum concentrations and urinary excretions of intact azodisalicylate after a single oral dose of $500 \mathrm{mg}$ disodium azodisalicylate. The two subjects represent the extremes of the observed range of values.

implying a long serum half-life. The serum concentrations of 5-ASA were very low and were undetectable in most of the subjects. Low concentrations of $\mathrm{N}$-acetyl-5-ASA were found in the serum, the maximum being $4.5 \mu \mathrm{mol} / 1(0.9 \mu \mathrm{g} / \mathrm{ml})$. Peak serum concentrations of N-acetyl-5-ASA did not occur until eight to 12 hours after the ingested dose.

Less than $5 \%$ of the ingested dose of disodium azodisalicylate appeared in the urine in the intact form (range $=0 \cdot 3-4 \cdot 4 \%$ ), while $19-41 \%$ (median $26.7 \%$ ) of the dose was recovered from the urine as 5-ASA and $\mathrm{N}$-acetyl-5-ASA. The faeces contained $7-36 \%$ (median $17.3 \%$ ) of the original dose in the form of 5-ASA and N-acetyl-5-ASA.

\section{EIGHT-DAY EXPERIMENT}

After an interval of two weeks, the same eight subjects took $500 \mathrm{mg}$ disodium azodisalicylate twice a day for eight days, the morning dose at $0900 \mathrm{~h}$ and the second dose after the evening meal. The intention was to achieve a steady state.

In the event, some of the subjects still had detectable amounts of intact disodium azodisalicylate in the serum at the start of the experiment and a steady state was not achieved by the end, so that 
subsequent experiments were conducted over a longer period. It is worth mentioning, however, that the 24-hour faecal excretion of total 5-ASA at the end of the eight-day study ranged from $18 \cdot 6-70 \cdot 3 \%$ (median $35.8 \%$ ) of the ingested dose.

\section{SIX-WEEK LOW-DOSE EXPERIMENT}

After a further interval of six weeks, four of the same subjects took $250 \mathrm{mg}$ disodium azodisalicylate daily at $0900 \mathrm{~h}$ for a period of six weeks. The main object of this experiment was to determine how long it took to reach a steady state and to ascertain the serum concentrations of azodisalicylate once such a state had been achieved. Figure 3 shows that a steady state was reached in all four subjects by 20-28 days. From these data it can be calculated that the serum half-time is 7.4-10 days. The actual serum concentrations found at steady state were very low and ranged from 3-8 $\mu \mathrm{mol} / \mathrm{l}(10-2 \cdot 8 \mu \mathrm{g} / \mathrm{ml})$. Two of the subjects were fast acetylators and two were slow acetylators, but this made no appreciable difference to the serum concentrations of the intact azodisalicylate.

\section{SIX-WEEK HIGH-DOSE EXPERIMENT}

After a further interval of three months, seven subjects took $2.0 \mathrm{~g}$ disodium azodisalicylate as a single daily dose each morning for a period of six weeks and were subsequently studied for a further

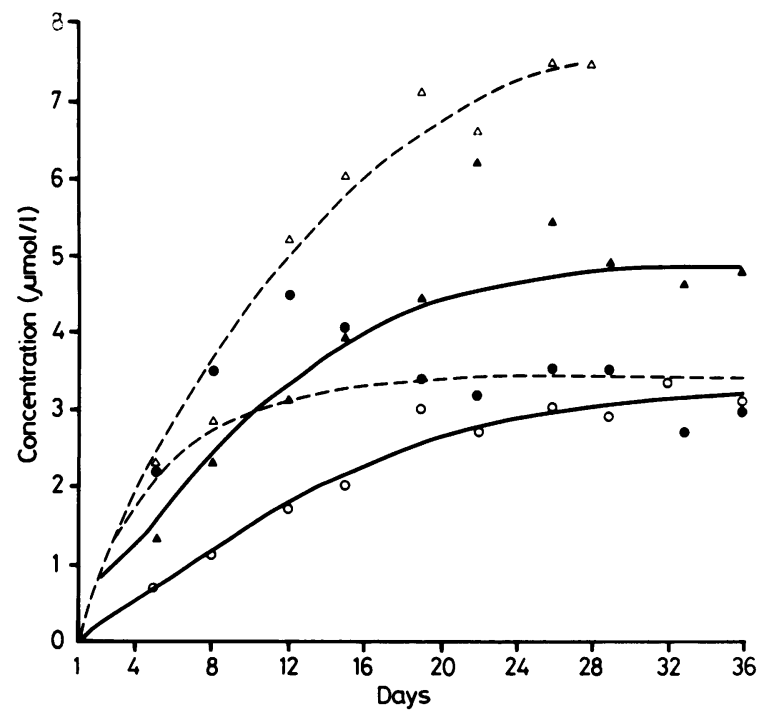

Fig. 3 Serum-concentration vs time curves of intact azodisalicylate in four subjects who took $250 \mathrm{mg}$ disodium azodisalicylate by mouth daily for six weeks. (Solid lines = fast acetylators; dotted lines = slow acetylators.) period of four weeks after the drug was stopped.

The main objects of this study were two-fold. Firstly, it gave an opportunity to observe any clinical, haematological, or biochemical adverse effects occurring in the subjects on a dose of disodium azodisalicylate which was equivalent in 5-ASA content to a therapeutic dose of sulphasalazine ( $4.6 \mathrm{~g}$ daily). Secondly, it permitted assessment of the steady-state serum concentrations and urinary and faecal losses occurring when the drug was being used at a dose that should be appropriate for therapeutic trial.

On the first of these points, there were no abnormal haematological or biochemical findings in this experiment or in the previous experiments. The details of the various investigations performed are given in the next section.

On the second of these points, the results were as follows:

\section{Serum concentrations}

Figure 4 shows the serum concentration vs time curves of disodium azodisalicylate in the two subjects whose steady-state concentrations were at the extremes of the range observed (12-36 $\mu \mathrm{mol} / \mathrm{l})$. The serum half-life could be calculated satisfactorily for six of the seven subjects and ranged from $4 \cdot 0-12 \cdot 8$ days (Table 1 ). This range of values is similar to that found in the six-week low-dose experiment, suggesting that the kinetics of disodium azodisalicylate are linear in the dose range studied

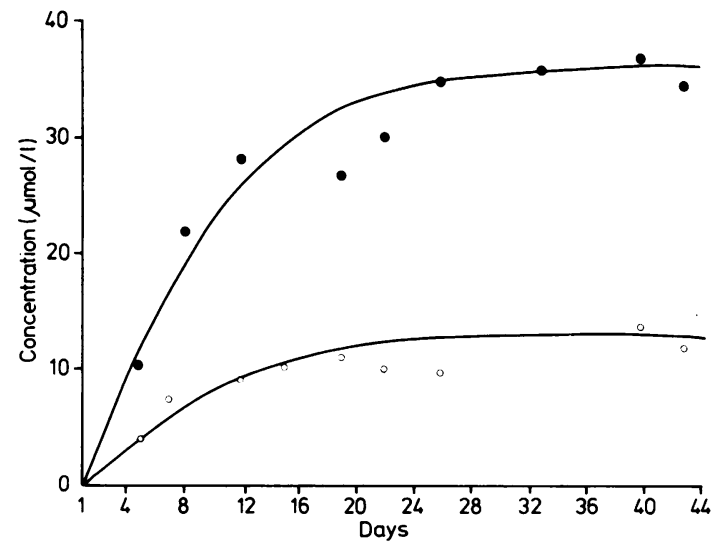

Fig. 4 Serum-concentration vs time curves of intact azodisalicylate in subjects taking $2.0 \mathrm{~g}$ disodium azodisalicylate by mouth daily for six weeks. The two subjects represent the extremes of the range of values observed. 
Table 1 Summary of disposition data for disodium azodisalicylate

\begin{tabular}{|c|c|c|c|c|c|c|c|}
\hline \multirow[b]{3}{*}{ Subject } & \multicolumn{2}{|c|}{ Half-time (day) } & \multirow{3}{*}{$\begin{array}{l}\text { Renal } \\
\text { clearance } \\
\text { (ml/min) }\end{array}$} & \multicolumn{2}{|c|}{ Urinary recovery (\%) } & \multirow{2}{*}{\multicolumn{2}{|c|}{ Faecal recovery $(\%)$}} \\
\hline & \multirow{2}{*}{$\begin{array}{l}\text { Steady-state } \\
\text { data }\end{array}$} & \multirow{2}{*}{$\begin{array}{l}\text { Disappearance } \\
\text { data }\end{array}$} & & \multirow{2}{*}{$\begin{array}{l}\text { Parent } \\
\text { compound }\end{array}$} & \multirow[b]{2}{*}{ Total 5-ASA } & & \\
\hline & & & & & & 5-ASA & $N-A c-5-A S A$ \\
\hline J & - & $5 \cdot 3$ & $1 \cdot 7$ & $0 \cdot 3$ & $18 \cdot 7$ & $1 \cdot 3$ & 1.8 \\
\hline A & $12 \cdot 8$ & $8 \cdot 5$ & $1 \cdot 3$ & 0.9 & $24 \cdot 2$ & $32 \cdot 0$ & $10 \cdot 0$ \\
\hline W & $9 \cdot 3$ & $8 \cdot 8$ & $1 \cdot 8$ & 0.9 & $14 \cdot 6$ & $33 \cdot 0$ & $13 \cdot 0$ \\
\hline $\mathbf{P}$ & $8 \cdot 4$ & 9.4 & $2 \cdot 2$ & $0 \cdot 5$ & $11 \cdot 8$ & $2 \cdot 4$ & $6 \cdot 8$ \\
\hline$T$ & $8 \cdot 8$ & $11 \cdot 0$ & $1 \cdot 6$ & 0.5 & $16 \cdot 1$ & 27.9 & $6 \cdot 1$ \\
\hline B & $12 \cdot 3$ & $8 \cdot 7$ & $1 \cdot 3$ & $0 \cdot 6$ & $18 \cdot 7$ & 1.9 & $2 \cdot 5$ \\
\hline$S$ & $4 \cdot 0$ & $5 \cdot 6$ & $1 \cdot 3$ & $0 \cdot 4$ & $15 \cdot 4$ & $21 \cdot 0$ & $16 \cdot 0$ \\
\hline Median & $9 \cdot 1$ & $8 \cdot 7$ & $1 \cdot 6$ & $0 \cdot 5$ & $16 \cdot 1$ & $21 \cdot 0$ & $6 \cdot 8$ \\
\hline
\end{tabular}

$(0 \cdot 25-2 \mathrm{~g}$ daily). The serum concentrations of 5-ASA were very low, the highest being $5.3 \mu \mathrm{mol} / \mathrm{l}$ and frequently being undetectable (median value $=0.7 \mu \mathrm{mol} / \mathrm{l})$. The range of $\mathrm{N}$-acetyl-5-ASA concentrations was $0-16.4 \mu \mathrm{mol} / \mathrm{l}$ (median $=5.6$ $\mu \mathrm{mol} / \mathrm{l})$. The half-life of disodium azodisalicylate was also calculated from measurements of serum concentrations made during the four weeks after the end of the six-week experimental period. The values ranged from 5·3-11 days, which corresponds closely to those calculated from the measurements made during the time of regular usage to steady state (Table 1).

\section{Urinary recovery}

At steady state, the urinary recovery of intact azodisalicylate ranged from $0.3-0.9 \%$ of the daily dose (median $=0.5 \%$ ). Urinary recovery of the sum of 5-ASA and N-acetyl-5-ASA ranged from $11.8 \%-24.2 \%$ of the equivalent intake $($ median $=16 \cdot 1 \%)$.

The renal clearance of azodisalicylate was calculated from the ratio of its total urinary recovery to the area under the serum-concentration $v s$ time curve both measured during a single dose interval at steady state. Values ranged from $1.3-2.2 \mathrm{ml} / \mathrm{min}$ (median $=1.6)($ Table 1$)$. These low values suggest that azodisalicylate is subject to extensive passive reabsorption in the renal tubules, as occurs with other salicylates.

\section{Faecal recovery}

Faecal recovery of disodium azodisalicylate was not measured as no satisfactory analytical method has yet been found. Faecal recovery of the sum of 5-ASA and $\mathrm{N}$-acetyl-5-ASA at steady state was $3 \cdot 1-46 \%$ of the equivalent daily dose (median $=34 \%)$ (Fig. 5). A substantial proportion was in the form of N-acetyl-5-ASA, the range being $18-72 \%$ of the total $($ median $=44 \%)$.

\section{LABORATORY INVESTIGATION OF POSSIBLE} ADVERSE EFFECTS

At the beginning and end of each of the four experiments described, a range of haematological and biochemical investigations was performed on all the subjects taking part. A specially extensive set of investigation (listed in Table 2) was performed in conjunction with the fourth experiment, in which

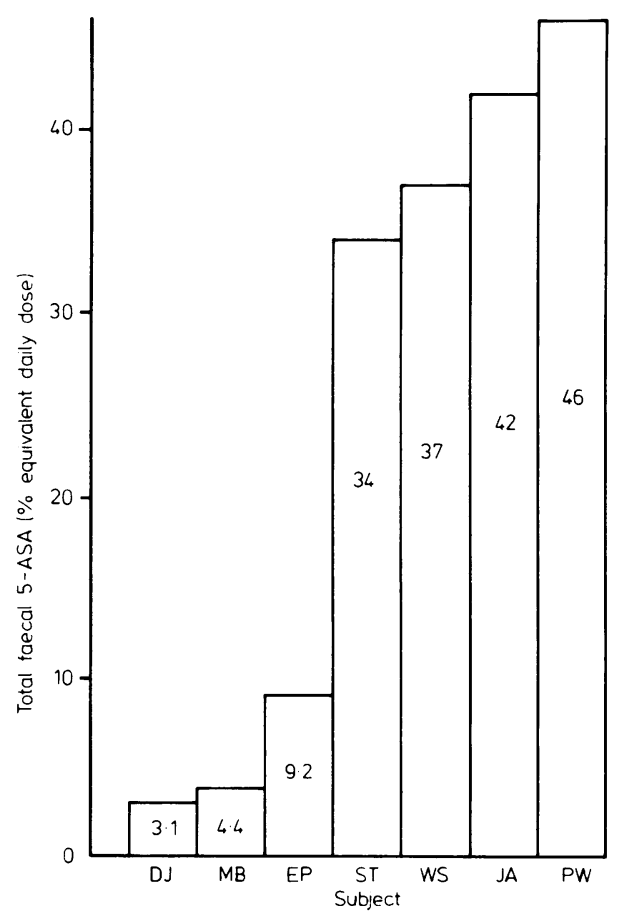

Fig. 5 Faecal recovery of total 5-ASA (5-ASA + N-acetyl5-ASA) in seven subjects at steady state while taking $2.0 \mathrm{~g}$ disodium azodisalicylate daily by mouth. 
Table 2 Investigations carried out at beginning and end of six-week high-dose experiment

\begin{tabular}{lc} 
Haemoglobin & Plasma urea and electrolytes \\
Red cell indices & Plasma calcium \\
(Coulter counter) & Plasma AsT, total protein, \\
Platelet count & albumin, alkaline phosphatase, \\
ESR & bilirubin \\
Heinz bodies & $\gamma$-Glutamyl transpeptidase \\
Coombs' test & Serum iron, total iron binding \\
Prothrombin time & capacity, folate, and vitamin \\
Microscopy and culture of a & $\mathrm{B}_{12}$ \\
mid-stream urine specimen & Serum immunoglobulins \\
\hline
\end{tabular}

the subjects were taking $2 \mathrm{~g}$ disodium azodisalicylate daily for six weeks. No abnormalities were found.

In the long-term experiments, template bleeding times were measured before taking the drug and when it had been in use for six weeks. There was no alteration in the bleeding time.

During the six-week high-dose experiment, the subjects made repeated tests of their own faeces for the presence of occult blood, using the commercial Fecatest kit. No evidence of occult bleeding was found.

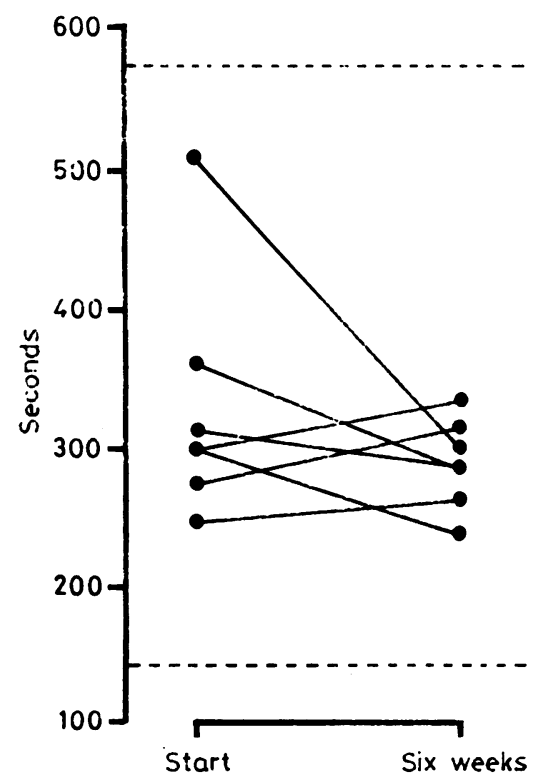

Fig. 6 Template bleeding times in seven subjects before and at the end of a six-week course of $2.0 \mathrm{~g}$ disodium azodisalicylate by mouth daily. The interrupted lines represent the normal range of values.

\section{Discussion}

It was our main aim in this study to determine the amounts of 5-ASA and $\mathrm{N}$-acetyl-5-ASA present in the colon after oral administration of disodium azodisalicylate, for comparison with the amounts present after oral administration of sulphasalazine, as 5-ASA and N-acetyl-5-ASA have both been shown to be effective in the treatment of active ulcerative colitis. ${ }^{7813} \mathrm{We}$ also took the opportunity of studying the serum half-time of disodium azodisalicylate, and its urinary excretion, as well as the urinary excretion of its metabolites, 5-ASA and $\mathrm{N}$-acetyl-5-ASA.

The recovery of total 5-ASA (5-ASA plus Nacetyl-5-ASA) from the faeces varied from $3 \cdot 1$ to $46 \%$ (median $=34 \%$ ) of the dose during a single dosage interval - that is, 24 hours - at steady state. This compares well with the results of Peppercorn and Goldman with sulphasalazine. ${ }^{6}$ They found in volunteers that, after steady-state therapy, $50 \%$ of a further single oral dose of sulphasalazine could be recovered as 5-ASA in the faeces collected over the 72 hours after the dose. Furthermore, the steadystate urinary recovery of total 5-ASA (12.3-25.1\% of the ingested dose, Table 1). in our study is similar to the values for recovery of 5-ASA found by others after the oral administration of sulphasalazine, ${ }^{56}$ suggesting that similar amounts of total 5-ASA are formed in the colon after administration of both sulphasalazine and disodium azodisalicylate.

It should be noted that, although the faecal recovery of total 5-ASA was very low in some of our subjects, there was no corresponding decrease in the recovery of total 5-ASA from the urine and we believe that the low values of faecal recovery in these subjects were due to the technical difficulties involved in making measurements of 5-ASA and $\mathrm{N}$-acetyl-5-ASA in faeces.

The total urinary recovery of disodium azodisalicylate, plus the urinary and faecal recovery of total 5 -ASA in our study was 21.5 to $67.1 \%$ (median $=50.6 \%$ ) at steady state, leaving $50 \%$ of the total dose unaccounted for. Because of the difficulties in detecting total 5-ASA in the faeces we are unable to say to what extent this incomplete recovery was due to the faecal excretion of disodium azodisalicylate, and to what extent due to other unidentified factors.

The half-time of disodium azodisalicylate in our volunteers was very long (4-12.8 days). This could be due to low rate of total clearance, a high apparent volume of distribution, or combination of the two. We have at present little evidence on which to base firm conclusions about the mechanisms involved, but can speculate by using the analogy of the 
disposition of sulphasalazine: ${ }^{14}$ sulphasalazine is poorly metabolised by the liver and has low rates of urinary and biliary clearance. Disodium azodisalicylate also has a low urinary clearance rate and is very likely to be poorly metabolised by the liver, as its initial metabolism depends on the same reaction as for sulphasalazine. Despite its low clearance rate, however, sulphasalazine has a relatively fast halftime (less than 10 hours), because of its low apparent volume of distribution $(<91)$. We therefore think that the apparent volume of distribution of disodium azodisalicylate must be relatively high, given its longer half-time. If the rates of clearance of the two drugs are the same, then the apparent volume of distribution of disodium azodisalicylate must be of the order of 100-200 l. Disodium azodisalicylate is poorly protein-bound (Agback, unpublished observations) while sulphasalazine is bound in excess of $95 \%{ }^{14}$ and that difference would be sufficient to account for the magnitude of difference that we propose between the apparent volumes of distribution of the two drugs.

As to the extent of absorption of disodium azodisalicylate, we have little information on which to speculate at present. The low urinary recovery of the drug (Table 1) suggests relatively poor absorption, as is the case for sulphasalazine,${ }^{14}$ but we have no way of correcting this absorption figure for the contribution of biliary excretion of drug or metabolites. The presence of N-acetyl-5-ASA in the faeces provides no information on the extent of biliary excretion since colonic bacteria can acetylate 5-ASA, as has been shown in vitro (Willoughby and Truelove, unpublished observations).

\section{Conclusions}

Our study has shown that the disposition of disodium azodisalicylate is similar in important respects to that of sulphasalazine. With both drugs it appears that a large proportion of the ingested dose reaches the colon where the colonic bacteria split the parent compound at the azo bond. The important difference is that, while sulphasalazine gives rise to 5-ASA and sulphapyridine, disodium azodisalicylate yields only 5-ASA. As both 5-ASA and $\mathrm{N}$-acetyl-5-ASA are effective in the treatment of ulcerative colitis by a topical effect on the inflamed mucosa, ${ }^{7813}$ disodium azodisalicylate is potentially a suitable drug for the treatment of ulcerative colitis. As it does not contain sulphapyridine, there is the possibility of using doses which will result in higher concentrations of 5-ASA in the colonic lumen than is feasible with sulphasalazine. It can also be anticipated that adverse effects will be fewer. In this study there were no adverse effects during six weeks of treatment with $2 \mathrm{~g}$ disodium azodisalicylate daily.

JKA is supported by the Wellcome Trust.

\section{References}

1 Baron JH, Connell AM, Lennard-Jones JE, Jones FA. Sulphasalazine and salicylazosulphadimidine in ulcerative colitis. Lancet 1962; 1: 1094-6.

2 Dick AP, Grayson MJ, Carpenter RG, Petrie A. Controlled trial of sulphasalazine in the treatment of ulcerative colitis. Gut 1964; 5: 437-42.

3 Misiewicz JJ, Lennard-Jones JE, Connell AM, Baron $\mathrm{JH}$, Jones FA. Controlled trial of sulphasalazine in maintenance therapy for ulcerative colitis. Lancet 1965; 1: $185-8$.

4 Dissanayake AS, Truelove, SC. A controlled therapeutic trial of long-term maintenance treatment of ulcerative colitis with sulphasalazine (Salazopyrin). Gut 1973; 14: 923-6.

5 Schröder H, Campbell DES. Absorption, metabolism and excretion of salicylazosulfapyridine in man. Clin Pharmacol Ther 1972; 13: 539-51.

6 Peppercorn MA, Goldman P. Distribution studies of salicylazosulfapyridine and its metabolites. Gastroenterology 1973; 64: 240-5.

7 Azad Khan AK, Piris J, Truelove SC. An experiment to determine the active therapeutic moiety of sulphasalazine. Lancet 1977; 2: 892-5.

8 van Hees PA, van Tongeren $\mathrm{JH}$, Bakker JH, van Lier HJ. Active therapeutic moiety of sulphasalazine. Lancet 1978; 1: 277.

9 Das KM, Eastwood MA, McManus JPA, Sircus W. Adverse reactions during salicylazosulfapyridine therapy and the relation with drug metabolism and acetylator phenotype. $N$ Engl J Med 1973; 289: 491.

10 Azad Khan AK, Howes DT, Piris J, Truelove SC. Optimum dose of sulphasalazine for maintenance treatment in ulcerative colitis. Gut 1980; 21: 232-40.

11 van Hees PAM. Clinical and pharmacological aspects of sulphasalazine. Nijmegen: Thesis, 1979.

12 Wagner JG. Fundamentals of clinical pharmacokinetics. Hamilton, Illinois: Drug Intelligence Publications Inc, 1975.

13 Willoughby CP, Piris J, Truelove SC. The effect of topical $\mathrm{N}$-acetyl-5-aminosalicylic acid in ulcerative colitis. Scand J Gastroenterol 1980; 15: 715-9.

14 Azad Khan AK, Truelove SC, Aronson JK. The disposition and metabolism of sulphasalazine (salicylazosulphapyridine) in man. Br J Clin Pharmacol 1982; 13: 523-8. 